\title{
Real Time Bus Tracking System
}

\author{
Akshay Sonawane \\ Computer Engineering \\ Shah And Anchor Kutchhi Engineering College \\ Mumbai, India \\ Ankeet Bhanushali \\ Computer Engineering \\ Shah And Anchor Kutchhi Engineering College \\ Mumbai, India
}

\author{
Kushal Gogri \\ Computer Engineering \\ Shah And Anchor Kutchhi Engineering College \\ line 3-Mumbai, India \\ Milind Khairnar \\ Assistant Professor \\ Shah And Anchor Kutchhi Engineering College \\ Mumbai, India
}

\begin{abstract}
In the busy metropolitan cities like Mumbai, Delhi, people don't have time to invest in waiting for transport. Waiting time for transport in such crowded cities leads to less productivity on a whole. People face this problem in their daily life where they have no idea about the current status of their transport. So the proposed solution is an android based application that will help the user to check out the current location of the bus and also will help the user to know how much time the bus will take to reach the current location of the user. The system will use GPS as the basis for the application and basic android application will be interfacing with the updated database to provide the real-time data to the user, hence enhancing the user-experience.
\end{abstract}

Keywords_-GPS Module, Android Studio.

\section{INTRODUCTION}

There are buses available for passengers travelling to different locations, but not many passengers have complete information about these buses. Complete information namely the number of buses that go to the required destination, bus numbers, bus timings, the routes through which the bus would pass, time taken for the vehicle to reach its destination location would assist the passengers with various routes, track the current location of the bus and give the correct time for the bus to reach its destination. The proposed system deals with overcoming the problems stated above. The system is an Android application that gives necessary information about all the buses travelling in Mumbai. The platform chosen for this kind of system is android, reason being Android Operating System has come up on a very large scale and is owned by almost every second person. As more and more applications of android operating system is developed day by day on large scale ever since it is arrival

\section{LITERATURE SURVEY}

A vehicle tracking system is very useful for tracking the movement of a vehicle from any location at any time. In this work, real time Google map and GPS based vehicle tracking system is implemented. These are some of the technical literature in engineering and technology where people have tried to implement similar kind of Systems which are mentioned below with their shortcomings with respect to our Application

[1]Authors "ManiniKumbhar, MeghanaSurvase, Pratibha MAvdhutSalunk" have implemented "Real Time Web Based Bus Tracking System" The proposed system reduces the waiting time of remote users for bus. A system is used to track the bus at any location at any time. All the current information is stored to the server and it is retrieved to remote users via web based application. This System is a web based system but nowadays people mostly tends to use Android apps since they are more portable and smart phones are used more widely in today's world. Also a web based system is inconvenient for a user to use on a regular basis while waiting for a bus at the bus stop.

[2]Authors "M. A. Hannan, A. M.Mustapha,A.Hussain and H. Basri" have implemented the system "Intelligent Bus Monitoring and Management System" The proposed system uses Artificial intelligence with the help of RFID module which is used in-order to reduce the manual work carried out in the Bus-Management \& Monitoring System. In this a RFID is used to track a bus when it crosses the bus stop. Hence the exact location of the bus is not shown, only an approximate location is shown based on the bus stops. In today's world, accuracy is very important and hence this was the limitation of this project.

[3]Authors "Süleyman Eken, Ahmet Sayar" have implemented" have implemented the system "A smart Bus Tracking System based on location- aware service and QR code." In this paper, Bus tracking system, any passenger with Smartphone can scan QR code placed at bus stop to view estimated bus arrival times, current location of the bus. The drawback in this project was that the user had to be physically present at the bus stop to scan the QR code.

[4]Authors "R.Maruthi, C.Jayakumari" implemented the system "SMS based Bus Tracking System using Open Source Technologies." A bus tracker application to track a bus using GPS transceiver has been proposed in this paper. The objective of this work is to develop a system that manages and controls the transport using a tracking device to know the scheduled vehicle and the current location of the vehicle via SMS using a GPS tracking device.

[5]Author "Yusuf Abdullahi Badamasi" have implemented the system "RFID bus ticketing system" with the help of RFID card which discard the manual or traditional ticketing system(Conductor)

[6] Authors "Md. Marufi Rahman, Jannatul Robaiat Mou, Kusum Tara, Md. Ismail Sarkar" have implemented the system "Real Time Google Map and Arduino Based VehicleTracking System" using GSM and Arduino coordinates sent by arduino is shown on google maps. 
[7] Authors "Manish Chandwani, Bhoomika Batheja, Lokesh Jeswani,Praveen Devnani, Prof. Richard Joseph" have implemented the system "Real Time Bus Tracking System".

\section{OVERVIEW OF PROPOSED SYSTEM}

\section{A. Abbreviations and Acronyms}

To create a mobile application which helps the daily travellers of bus to track the location of the bus? The application would allow the users to search the bus which they want through bus numbers and will show the live location of the bus.

\section{B. Objective}

- To give the user the exact location of the selected bus with respect to the user location.

- To give approximate distance and time of the bus from the user location using distance matrix api.

- Give a list of bus numbers for particular source and destination.

\section{Methodology}

The application provides the live location of the bus to the user. The commuters can not only fetch the bus location but also know estimate time taken by bus to reach its destination. The Location information is fetched from the online database which receives the data regarding the location from a separate application used by drivers/conductors on the bus. This helps in maintaining the uniqueness of the bus while displaying its location on the map. The request made by the client for the bus information will be fetched from the database and delivered to client through server.

The driver/conductor will send its coordinates continuously to our server where data will be stored. When the user selects that particular Bus ID, its location will be retrieved from the server and shown on the map. Since the coordinates will be changing, the point on the map will keep on moving, hence the user can actually see the live location of the selected bus. Also we will use google's distance matrix algorithm to show the user the approximate time taken by bus to reach the user. The application will be developed using android studio which has a very simple User Interface to use it. Google maps API is the core component that will be used in it, which is very easy to use and explore maps with simple gestures such as pinch to zoom tap to point etc. It will make tracking the bus very easy for the user.

\section{Block Diagram}

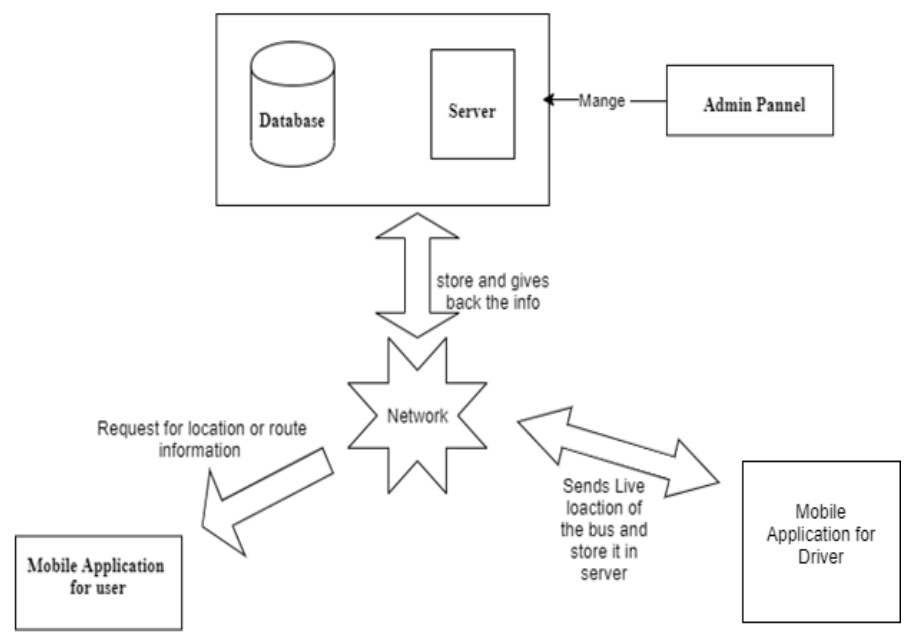

Figure I. Block Diagram

\section{E. Flow Chart}

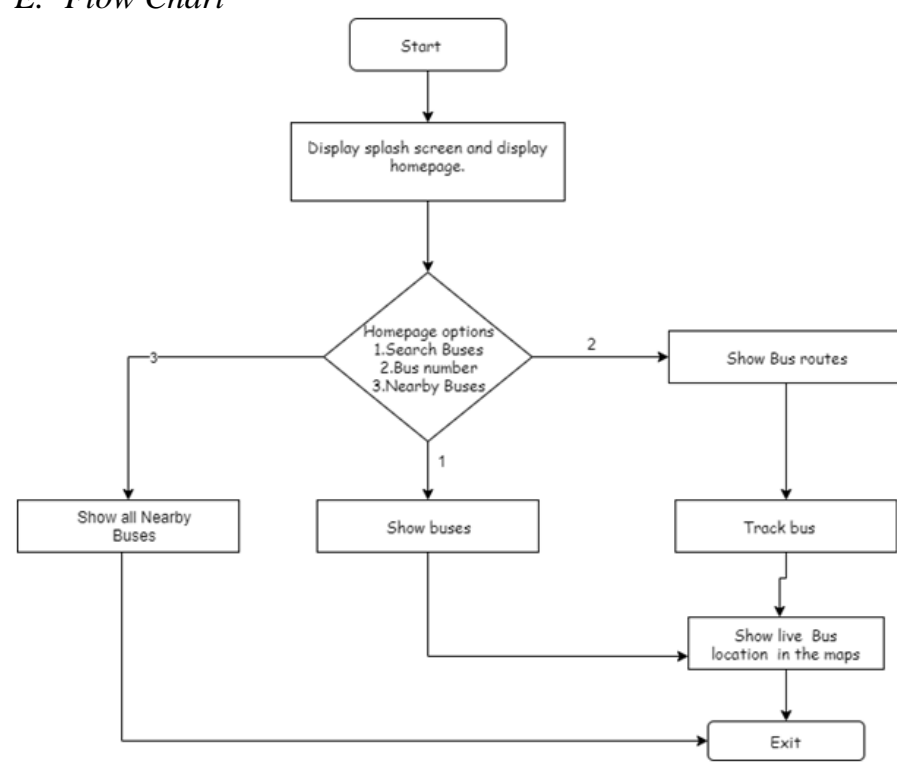

Figure II. Flow Chart

IV. SUMMARY

The system allows a user to track their bus from the android app. With the help of tracking user can see how far the bus is this allows user to plan their route and travel plan accordingly. App will also give the approximate time and distance of the bus. This will reduce the wait time increased willingness to pay and customer satisfaction. Along with the tracking user can also buy a ticket from the app when they are in the bus. This android application will make bus transportation more productive.

\section{SCOPE}

The main goal of the proposed work is to improve the Bus Tracking system by adding the necessary features to our project, like projecting accurate bus timings, presenting correct bus numbers and by adding a GPS tracker into it for accurate locations.

For future enhancement, we can develop a vehicle monitoring system using GPS \& GSM module with high speed processor. The system can be installed in buses, cars and trucks, hence 
this project is having a wide scope. Along with this we can create a bus ticketing system where the user can actually buy a digital ticket just like the UTS app in the mumbai railways. in which app take the current location of the user ask for the destination and calculate the fare we will also provide pay option from various third party app such as Paytm , PayPal etc.

We can generalize the project to common man where he can implement the hardware part to the personal vehicles which will help them to track their location after it has been stolen it will also police. We can also extend it to private travel agency to track there bus.

\section{REFERENCES}

[1] Eddie Chi-Wah Lau, "Simple Bus Tracking System', Journal of Advanced Computer Science and Technology Research, vol.3, no.1, 2013

[2] Khondker Shajadul Hasan, Mashiur Rahman, Abul L. Haque, M Abdur Rahman, Tanzil Rahman, and M Mahbubur Rasheed, "Cost Effective GPS-GPRS Based Object Tracking System," Proceedings of the International MultiConference of Engineers and Computer Scientists 2009 (IMECS 2009), March 2009, Hong Kong, vol. 1.

[3] MZ Parvez, KZ Ahmed, QR Mahfuz, MS Rahman," A theoretical model of GSM network based vehicle tracking system," 2010 International Conference on Electrical and Computer Engineering (ICECE), Dec. 2010, pp. 594-597.

[4] https://en.wikipedia.org/wiki/Arduino

[5] https://www.dfrobot.com/wiki/index.php/GPS/GPRS/GSM_Module_ V3.0_(SKU:TEL0051) 